https://doi.org/10.23913/ride.v11i21.712

Artículos científicos

\title{
Desarrollo de un software educativo para la orientación- aprendizaje de la detección del cáncer cervicouterino
}

\author{
Development of an Educational Software for the Orientation-Learning of \\ Cervical Cancer Detection
}

\section{Desenvolvimento de um software educacional para o aprendizado de orientação na deteç̧ão de câncer cervical}

\author{
Argeo Romero Vázquez \\ Universidad Juárez Autónoma de Tabasco, México \\ argeoromero@hotmail.com \\ https://orcid.org/0000-0002-9444-4889 \\ Francisco López Jiménez \\ Indautosoft SA de CV. Monterrey, México \\ fljimenez@hotmail.com \\ https://orcid.org/0000-0003-2371-6602
}

\section{Resumen}

El objetivo de este trabajo fue construir y evaluar la utilidad de un software educativo para la orientación-aprendizaje de la detección del cáncer cervicouterino que contempla aspectos psicopedagógicos. Metodológicamente, con la ayuda de especialistas en programación y docencia y con un enfoque cognitivista-constructivista, se desarrollaron varios prototipos evolutivos con refinamientos sucesivos, incluyendo en el software información acerca del cáncer cervicouterino, la toma de la muestra de citología cervical y la toma de muestra para la detección del virus del papiloma humano por captura de híbridos. Para la evaluación contextualizada, se presentó el software desarrollado a estudiantes de medicina, con un grupo control (A) y dos grupos experimentales (B y C). Al comparar los resultados antes y después de la intervención, se demostró la eficacia del producto en cuanto al logro de aprendizajes significativos. 


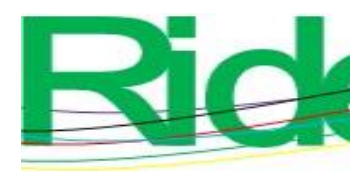

Revista Iberoamericana para la Investigación y el Desarrollo Educativo

ISSN 2007 - 7467

Palabras clave: cáncer cervicouterino, cérvix, híbridos, software educativo, virus del papiloma humano.

\section{Abstract}

The objective of this work was to build and evaluate the usefulness of an educational software for the orientation-learning of cervical cancer detection that considers psycho-pedagogical aspects. Methodologically, with the help of programming and teaching specialists and with a cognitive-constructivist approach, several evolutionary prototypes were developed with successive refinements, including in the software information about cervical cancer, the taking of the cervical cytology sample and the taking of sample for detection of human papillomavirus by capture of hybrids. For contextualized evaluation, the software developed was presented to medical students, with a control group (A) and two experimental groups (B and C). By comparing the results before and after the intervention, the efficacy of the product in terms of achieving significant learning was demonstrated.

Keywords: cervical cancer, cervix, hybrids, educational software, human papillomavirus.

\section{Resumo}

O objetivo deste trabalho foi construir e avaliar a utilidade de um software educacional para o aprendizado-orientação da deteç̧ão do câncer de colo uterino que considera aspectos psicopedagógicos. Metodologicamente, com a ajuda de especialistas em programação e ensino e com uma abordagem cognitivo-construtivista, vários protótipos evolutivos foram desenvolvidos com aprimoramentos sucessivos, incluindo no software informações sobre câncer de colo uterino, a coleta da amostra de citologia cervical e a coleta de amostra para detecção de papilomavírus humano por captura de híbridos. Para avaliação contextualizada, o software desenvolvido foi apresentado aos estudantes de medicina, com um grupo controle (A) e dois grupos experimentais (B e C). Ao comparar os resultados antes e após a intervenção, foi demonstrada a eficácia do produto em termos de obtenção de aprendizado significativo.

Palavras-chave: câncer cervical, colo do útero, híbridos, software educacional, vírus do papiloma humano. 


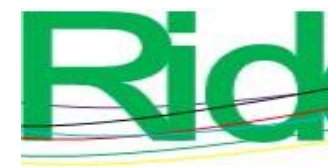

Fecha Recepción: Febrero 2020
Revista Iberoamericana para la Investigación y el Desarrollo Educativo ISSN $2007-7467$

\section{Introducción}

Pérez (2002) refiere que "la generación, aplicación, e integración de las herramientas informáticas dentro de nuestras actividades cotidianas evidencian que nos encontramos dentro de nuevas realidades, las cuales no podemos pretender abarcar analítica y conceptualmente con proposiciones del pasado" (p. 177). Así, a estas alturas resulta irrefutable que las tecnologías de la información y la comunicación (TIC) "están creando nuevos ambientes para la enseñanza y el aprendizaje" (Pérez, 2002, p. 177). En entornos clínicos, por ejemplo, se han utilizado estas nuevas herramientas, la realidad virtual entre ellas, con resultados favorables para el entrenamiento del potencial usuario (Montana, Tuena, Serino, Cipresso y Riva, 2019). Este nuevo paradigma exige la construcción de nuevos modelos educativos, como el modelo telemático, el cual "aporta ventajas de integración, interactividad, flexibilidad y superación de distancias físicas, que le convierten en el medio más adecuado para realizar diversas acciones pedagógicas, muy especialmente en la formación continua y a distancia" (Pérez, 2002, p. 153).

El software educativo resulta necesario por el creciente uso de las TIC en la sociedad actual, y el potencial que tienen para apoyar en los procesos formativos. Como parte de estos nuevos caminos, el profesor debe elaborar materiales curriculares dinámicos, interactivos, con contenidos motivadores y de fácil manejo por los estudiantes (Olivar y Daza, 2007).

De acuerdo con Peñalosa y Castañeda (2008), un modelo de generación de conocimiento para el aprendizaje en Internet debe estar sustentando en tres grandes pilares:

1) el diseño del ambiente de aprendizaje y la interactividad pensando en el estudiante, como ente activo y protagonista en el proceso;

2) la incorporación de funciones para el fomento de la construcción de conocimiento; y

3) la incorporación de funciones para el fomento de habilidades de aprendizaje autorregulado (p. 252).

Igualmente, cabe traer a colación la advertencia de Pérez (2002), quien, si bien habla sobre la telemática en específico, aquí se hace extensiva a la aplicación general de la tecnología en el ámbito educativo, menciona que independientemente de las aportaciones 


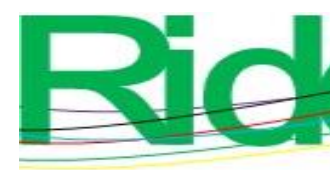

Revista Iberoamericana para la Investigación y el Desarrollo Educativo ISSN $2007-7467$

que se pueden derivar de las TIC a favor de la mejora educativa, a raíz de que se trata de medios relativamente nuevos, algunos de ellos aún en desarrollo, "su implementación debe estar sujeta a determinados controles que permitan valorar adecuadamente no sólo su calidad global, sino también su efecto diferencial sobre otras opciones de formación (p. 153).

Para Núñez (2008), "las nuevas tecnologías desempeñan un papel fundamental en la aparición de las redes de enseñanza superior” (p. 168). Romero (2010), por su parte, añade que el dinamismo que impera en la actualidad "exige un alto nivel de competitividad en términos de eficiencia, eficacia y efectividad" (p. 20).

Teniendo en cuenta lo descrito hasta aquí, el objetivo fue construir y evaluar la utilidad de un software educativo para la orientación-aprendizaje de la detección del cáncer cervicouterino que contempla aspectos psicopedagógicos. Se trata de desarrollar un producto de calidad que satisfaga las necesidades del usuario al que va dirigido (García, Vite, Navarrate, García y Torres, 2016).

\section{Método}

Para el diseño y desarrollo del software, se realizaron prototipos evolutivos con refinamientos sucesivos, integrando los instrumentos de representación clásicos del enfoque cognitivista-constructivista, construyendo la herramienta educativa desde un aspecto integral, con la contribución de diferentes áreas del saber, considerando los aspectos pedagógicos en el ciclo de vida con la participación de especialistas en contenidos de diseño de software. A partir de ello, se logró integrar el diseño de los contenidos con estrategias cognitivas y estructurar adecuadamente los conceptos, con una definición clara del tema y los objetivos para que el estudiante pueda acceder al conocimiento por medio de las actividades propuestas (Cataldi, 2000). Así, se presentó la propuesta de evaluación de cada prototipo a 13 estudiantes del tercer ciclo de la licenciatura de Médico Cirujano (2014-1) de la División Académica de Ciencias de la Salud de la Universidad Juárez Autónoma de Tabasco (UJAT). Posteriormente, se siguió el plan de incorporación de las modificaciones sugeridas, con base en los cuestionarios de valoración (considerando aspectos de la interfaz de comunicación y de los contenidos desarrollados), en donde se reflejó el grado de conformidad del usuario con una escala de valoración para cada ítem que iba del uno al cinco: 5 = Excelente, 4 = Muy bueno, 3 = Bueno, 2 = Regular y 1 = Malo, lo cual permitió obtener

una puntuación de los aspectos considerados, y formular o modificar aquellos que hayan 


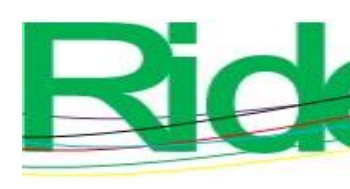

Revista Iberoamericana para la Investigación y el Desarrollo Educativo ISSN $2007-7467$

tenido puntuación menor a 2.5 (Cataldi, 2000). Además, para la evaluación externa, se presentó el programa a nueve docentes y profesionales vinculados con la salud pública.

Para el desarrollo y evaluación del software fue necesario un contexto educativo, ambiente para el cual se creó el programa, y así lograr la denominada evaluación contextualizada, ya que este tipo de evaluación se considera como la más representativa porque da cuenta de las reacciones de los potenciales usuarios entre el programa y, por lo tanto, de la eficacia del producto (Cataldi, 2000). Para lograr dicho propósito, se consideraron los siguientes criterios: interfaz de comunicación (Prototipo v1 [versión uno]), contenidos y pertinencia (Prototipo v2 [versión dos]), utilidad, pedagógicos y didácticos y técnicos (Prototipo vfinal [versión final]).

Llegado a este punto, vale la pena hacer un paréntesis y definir software educativo, tarea para la cual se recurre a Cataldi (2000), quien lo plantea de la siguiente manera:

A los programas de computación realizados con la finalidad de ser utilizados como facilitadores del proceso de enseñanza y consecuentemente de aprendizaje, con algunas características particulares tales como: la facilidad de uso, la interactividad y la posibilidad de personalización de la velocidad de los aprendizajes (p. 18).

Ahora bien, retomando los pasos que se llevaron, se determinó la factibilidad y el ciclo de vida del software desde la perspectiva de la relación costo-beneficio, al considerar las necesidades del programa educativo, y se seleccionó un modelo para el programa de acuerdo con la teoría de aprendizaje elegida (Cataldi, 2006). En este caso, se identificó a los responsables de cada tarea $\mathrm{y}$, una vez hecho esto, se planificó la garantía de calidad y viabilidad del software.

A sabiendas del tipo de programa a desarrollar, se definieron los requerimientos de la interfaz y la interactividad, a la par de que se desarrollaron los requisitos del software, priorizando e integrando los requisitos educativos. En cuanto a la etapa de diseño detallado del prototipo, definida como la "especificación verificada de la estructura de control, la estructura de los datos, las relaciones de interfaces, el tamaño, los algoritmos básicos y las suposiciones de cada componente del programa” (Guzmán, Durley y López, 2014, p. 69); en esta etapa, decíamos, se documentaron, según Guzmán et al. (2014), "los algoritmos que llevarán a cabo la función a realizar por cada uno de los módulos” (p. 69). 


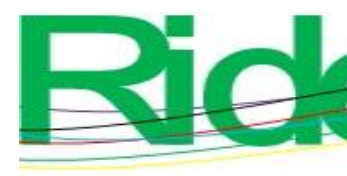

Revista Iberoamericana para la Investigación y el Desarrollo Educativo ISSN 2007 - 7467

Cabe señalar que para el diseño del software se tomaron en cuenta cuatro atributos: 1) la estructura de datos, 2) la arquitectura del software, 3) el detalle procedimental y 4) la caracterización de la interfaz (Cataldi, 2000, p. 79). Además de las etapas del ciclo de vida, se observaron, en el diseño del sistema final, los procesos de implementación e integración de módulos. Aquí se consideró la creación de los datos de prueba, crear el código fuente, generar el código objeto, crear la documentación de operación y planificar la integración de los módulos (Cataldi, 2000).

Asimismo, se consideró oportuno realizar un software interactivo con las siguientes tecnologías: HTML5, JavaScript y jQuery. Todas estas tecnologías se utilizaron para hacer aplicaciones abiertas. Dicha elección permitió ejecutar el software desde un DVD y, al mismo tiempo, permitió migrar la información a un portal de Internet, gracias a lo cual más usuarios puedan hacer uso de la información (Romero, 2014).

Al terminar el desarrollo del software educativo para la orientación-aprendizaje de la detección del cáncer cervicouterino, se sometió a una evaluación por parte de potenciales usuarios, con la finalidad de verificar la eficacia del producto en cuanto al logro de aprendizajes significativos. Por conveniencia, se seleccionaron tres grupos para validar la comprensión del material educativo: un grupo control, grupo A (23 estudiantes), y dos experimentales, B (25 estudiantes) y C (10 estudiantes). Los participantes pertenecían al turno vespertino del tercer ciclo (2014) de la licenciatura Médico Cirujano de la División Académica de Ciencias de la Salud de la UJAT, México. En el grupo A, un integrante presentó el tema, los demás recibieron la información. Algunos, al igual que el coordinador del grupo (profesor), preguntaron y realizaron comentarios en relación con el tema del cáncer cervicouterino. En cuanto al grupo B, la clase fue similar al grupo A, solo que aquí el profesor entregó el software educativo para la orientación-aprendizaje de la detección del cáncer cervicouterino, cuyo listado de tópicos, imágenes y videos sirvieron como complemento de estudio de este tema y otros. En el grupo C, el coordinador del grupo les indicó a los participantes estudiar el tema de cáncer cervicouterino señalado en el programa de la asignatura de Salud Pública, e igualmente les entregó el software educativo como complemento educativo.

Los principales temas del software educativo para la orientación-aprendizaje de la detección del cáncer cervicouterino son: 


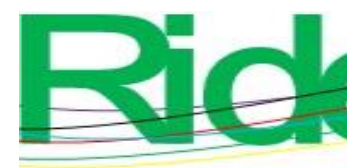

\section{Revista Iberoamericana para la Investigación y el Desarrollo Educativo ISSN 2007 - 7467}

- Generalidades del cáncer cervicouterino.

- La citología cervical.

- La toma de muestra para la detección del virus del papiloma humano (VPH) por captura de híbridos.

Antes y después de la intervención, se aplicó un cuestionario a cada grupo para verificar el rendimiento de los discentes. Para el análisis, se realizó una comparación entre variables o grupos pretest y postest. Se calculó la razón de posibilidad con su intervalo de confianza de $95 \%$ y un nivel de significación estadística de $p<0.05$. Por último, se utilizó el programa Epi-Info versión 6.04d, desarrollado por los Centros para el Control y la Prevención de Enfermedades en Atlanta, Georgia.

\section{Consideraciones éticas}

Para el grabado del video, se contó con profesionales en videofilmación, además de los sujetos voluntarios (estudiantes [evaluación de prototipos] y profesionales de la salud [evaluación externa]) a los que se les explicó el motivo de la investigación y aceptaron participar. Para la filmación de los procedimientos, toma de la muestra de citología cervical y la toma de muestra para la detección del VPH por captura de híbridos, previa explicación, se solicitó a los participantes el consentimiento firmado por escrito. Asimismo, para el uso de las instalaciones y equipos necesarios, respectivo consentimiento se solicitó al director de la unidad de salud; de la misma manera, al profesional de salud que realizó los procedimientos. El software desarrollado se presentó ante la Comisión de Bioética del Estado de Tabasco, México, la cual aprobó su pertinencia y utilidad para los usuarios.

\section{Resultados}

Diseño y desarrollo del software educativo para la orientaciónaprendizaje de la detección del cáncer cervicouterino

\section{Evaluación de la interfaz de comunicación. Prototipo v1}

Para la evaluación del Prototipo v1, se contó con la participación de 13 estudiantes de la licenciatura de Médico Cirujano de la UJAT. Los resultados cuantitativos se aprecian en la tabla 1. En este prototipo solo se presentó un prediseño de la pantalla, el menú 


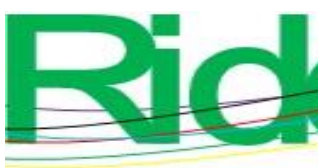

Revista Iberoamericana para la Investigación y el Desarrollo Educativo

ISSN $2007-7467$

desplegable y árbol de contenidos. Las imágenes, los videos y el sonido no estaban cargados aún.

Tabla 1. Plantilla de evaluación de la interfaz de comunicación de desarrollo del software educativo para la orientación-aprendizaje de la detección del cáncer cervicouterino.

Prototipo v1

\begin{tabular}{|c|c|c|c|c|c|c|c|c|c|c|c|c|c|c|}
\hline \multirow[t]{2}{*}{ Requisitos técnicos del software educativo } & \multicolumn{14}{|c|}{ Estudiantes evaluadores del prototipo } \\
\hline & 1 & 2 & 3 & 4 & 5 & 6 & 7 & 8 & 9 & 10 & 11 & 12 & 13 & Promedio \\
\hline $\begin{array}{l}\text { 1) ¿Considera adecuado el diseño general de la } \\
\text { pantalla? }\end{array}$ & 3 & 3 & 4 & 2 & 3 & 3 & 4 & 2 & 2 & 4 & 4 & 3 & 4 & 3.2 \\
\hline 2) ¿Considera adecuado el uso del menú? & 5 & 5 & 5 & 5 & 5 & 3 & 4 & 3 & 3 & 3 & 5 & 3 & 5 & 4.2 \\
\hline 3) ¿Considera adecuado el uso de los módulos? & 4 & 5 & 5 & 5 & 5 & 3 & 4 & 5 & 4 & 5 & 4 & 4 & 5 & 4.5 \\
\hline $\begin{array}{l}\text { 4) ¿Considera adecuado el uso de los enlaces } \\
\text { (hipervínculos)? }\end{array}$ & 4 & 5 & 5 & 5 & 5 & 5 & 5 & 4 & 4 & 5 & 4 & 4 & 5 & 4.6 \\
\hline 5) ¿Considera adecuado el uso de los colores? & 4 & 5 & 3 & 5 & 5 & 4 & 4 & 4 & 4 & 4 & 5 & 3 & 5 & 4.2 \\
\hline $\begin{array}{l}\text { 6) ¿Considera adecuado el uso de los tipos de } \\
\text { letras? }\end{array}$ & 5 & 5 & 3 & 4 & 3 & 2 & 5 & 2 & 2 & 3 & 4 & 3 & 3 & 3.4 \\
\hline 7) ¿Considera que el programa es interactivo? & 1 & 4 & 4 & 2 & 4 & 2 & 4 & 2 & 1 & 3 & 4 & 2 & 3 & 2.8 \\
\hline 8) ¿Considera la interfaz amigable? & 5 & 4 & 5 & 3 & 4 & 4 & 3 & 2 & 2 & 4 & 4 & 4 & 5 & 3.8 \\
\hline $\begin{array}{l}\text { 9) ¿Le da buena información acerca del } \\
\text { recorrido? }\end{array}$ & 5 & 4 & 5 & 5 & 5 & 4 & 4 & 3 & 5 & 4 & 4 & 4 & 5 & 4.4 \\
\hline $\begin{array}{l}\text { 10) ¿Considera criteriosa la secuenciación de } \\
\text { los Módulos? }\end{array}$ & 5 & 5 & 4 & 2 & 5 & 3 & 4 & 3 & 3 & 4 & 5 & 4 & 4 & 3.9 \\
\hline 11) ¿Es de fácil manejo? & 5 & 5 & 4 & 4 & 5 & 4 & 4 & 4 & 5 & 4 & 5 & 4 & 5 & 4.5 \\
\hline 12) ¿Ha despertado interés en usted? & 4 & 5 & 5 & 4 & 5 & 3 & 4 & 3 & 2 & 3 & 5 & 3 & 5 & 3.9 \\
\hline 13) Sugerencias de cambio $(1=$ Sí, $2=\mathrm{No})$ & 1 & 1 & 1 & 1 & 1 & 1 & 1 & 1 & 1 & 1 & 1 & 1 & 1 & \\
\hline \multicolumn{15}{|c|}{ Sugerencias de cambio } \\
\hline $\begin{array}{l}\text { 1) Colocar un menú de inicio, y colocar un botó } \\
\text { 2) Anexar foro de preguntas. } \\
\text { 3) Cambiar el tipo de letra y el color para que no } \\
\text { encabezados. } \\
\text { 4) Colocar páginas interactivas, videos o víncul } \\
\text { 5) Agregar imágenes al diseño y texto. } \\
\text { 6) Corregir las letras que presentan diéresis. } \\
\text { 7) Incluir un método para seguir las actualizacio } \\
\text { 8) La bienvenida debería ser más llamativa (imá } \\
\text { 9) Suscripción con correo electrónico. } \\
\text { 10) Es necesario mejor configuración. } \\
\text { 11) El color crema está un poco simple, requier } \\
\text { 12) Pasar el contacto al final. } \\
\text { 13) Colocar idiomas. } \\
\text { 14) Colocar un blog. }\end{array}$ & $\begin{array}{l}\text { par } \\
\text { se } c \\
\text {. }\end{array}$ & $\begin{array}{l}\text { a re } \\
\text { om }\end{array}$ & $\begin{array}{l}\text { gre } \\
\text { pin }\end{array}$ & co & $\mathrm{m}$ & fo & $\begin{array}{l}\mathrm{de} \\
\text { ddo }\end{array}$ & $\begin{array}{l}\text { inic } \\
\text { y re }\end{array}$ & $\begin{array}{l}\text { io. } \\
\text { esal }\end{array}$ & ar $n$ & lás la & s let & as d & los \\
\hline
\end{tabular}

Nota: Calificación del 1 al 5: 5 = Excelente, $4=$ Muy bueno, $3=$ Bueno, $2=$ Regular, $1=$ Malo)

Fuente: Elaboración propia 


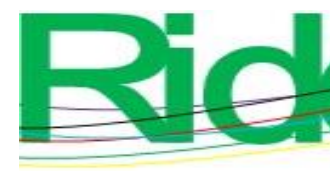

Revista Iberoamericana para la Investigación y el Desarrollo Educativo ISSN $2007-7467$

Los resultados cuantitativos del diseño de la pantalla parecieron adecuados. Los alumnos solicitaron mejorar los colores utilizados y los tipos de letras (tamaño, color). Además, se tuvo que mejorar la interactividad del programa: se hizo más dinámica por medio de imágenes y videos. La interfaz pareció fácil de navegar y la secuenciación de las pantallas en general fue considerada como buena y de fácil manejo. En general, hubo interés en observar las mejoras del siguiente prototipo del programa, con las nuevas funcionalidades incorporadas. Las sugerencias de cambio relevantes fueron básicamente cambiar el tipo de letra y el color para que no se combine con el fondo y resaltar más las letras de los encabezados, mejorar el menú de inicio y colocar un botón para regresar al menú de inicio, que el programa sea interactivo, con imágenes y videos, contacto por correo electrónico y que la bienvenida sea más atractiva.

\section{Evaluación de contenidos y pertinencia. Prototipo v2}

De acuerdo con las preguntas ponderadas y las sugerencias realizadas, se pasó al siguiente prototipo incremental. Se incluyeron las imágenes, algunos videos y la información acerca del cáncer cervicouterino, la toma de la muestra de citología cervical y la toma de muestra para la detección del VPH por captura de híbridos. Ahora se podría tener una idea mucho más cercana a lo que sería el programa finalizado. En este caso, las preguntas acerca de la interfaz de comunicación fueron pocas; se enfocaban más bien en aspectos relacionados con los contenidos y su pertinencia, se hacía mucho hincapié en la presentación de estos, la estructuración y la adecuación a las necesidades del grupo. En la tabla 2 se describen los resultados obtenidos con las ponderaciones y las sugerencias de los estudiantes. En términos generales, consideraron muy bueno el desarrollo de esta etapa del programa, referente la selección de los contenidos. Hubo aceptación positiva en cuanto los cambios sugeridos en el primer prototipo: estuvieron satisfechos con la interactividad, con el programa como un tutorial, con la buena resolución de los videos; aunque, sugirieron, estaría aún mejor con la inclusión del sonido. Respecto al resto de las sugerencias, quizás la más relevante es que el programa finalizado presente imágenes en los textos, mejorar la introducción de los videos, así como los hipervínculos en los textos, según sea necesario. 
Tabla 2. Evaluación de contenidos y pertinencia de desarrollo del software educativo para la orientación-aprendizaje de la detección del cáncer cervicouterino. Prototipo v2

\begin{tabular}{|c|c|c|c|c|c|c|c|c|c|c|c|c|c|c|}
\hline \multirow{2}{*}{$\begin{array}{c}\text { Contenidos y pertinencia del software } \\
\text { educativo }\end{array}$} & \multicolumn{14}{|c|}{ Estudiantes evaluadores del prototipo } \\
\hline & 1 & 2 & 3 & 4 & 5 & 6 & 7 & 8 & 9 & 10 & 11 & 12 & 13 & Promedio \\
\hline $\begin{array}{l}\text { 1) ¿Considera adecuado la selección de los } \\
\text { contenidos? }\end{array}$ & 4 & 5 & 5 & 4 & 5 & 5 & 5 & 5 & 5 & 4 & 5 & 4 & 5 & 4.7 \\
\hline $\begin{array}{l}\text { 2) ¿Consideraría adecuado el uso del } \\
\text { programa terminado en otros niveles? }\end{array}$ & 5 & 5 & 5 & 5 & 5 & 5 & 4 & 5 & 5 & 4 & 5 & 4 & 4 & 4.7 \\
\hline $\begin{array}{l}\text { 3) ¿Los cambios realizados fueron } \\
\text { pertinentes? }\end{array}$ & 3 & 5 & 5 & 2 & 5 & 4 & 5 & 5 & 5 & 4 & 5 & 3 & 4 & 4.2 \\
\hline $\begin{array}{l}\text { 4) ¿Quisiera que el programa fuera un } \\
\text { tutorial? }\end{array}$ & 2 & 5 & 5 & 5 & 5 & 5 & 4 & 5 & 5 & 4 & 5 & 4 & 3 & 4.4 \\
\hline $\begin{array}{l}\text { 5) ¿Le facilita la comprensión acerca del } \\
\text { tema? }\end{array}$ & 5 & 5 & 5 & 3 & 5 & 5 & 4 & 5 & 5 & 4 & 5 & 4 & 4 & 4.5 \\
\hline $\begin{array}{l}\text { 6) ¿Le gustaría que los videos tuvieran } \\
\text { sonido? }\end{array}$ & 5 & 5 & 5 & 5 & 5 & 5 & 5 & 5 & 4 & 5 & 5 & 5 & 3 & 4.8 \\
\hline 7) Sugerencias de cambio $(1=$ Sí, $2=$ No) & 1 & 1 & 1 & 1 & 2 & 1 & 1 & 2 & 1 & 1 & 2 & 1 & 1 & \\
\hline \multicolumn{15}{|c|}{ Sugerencias de cambio } \\
\hline \multicolumn{15}{|c|}{$\begin{array}{l}\text { 1) Colocar imágenes en temas. } \\
\text { 2) Colocar video en el menú principal. } \\
\text { 3) Agregar un efecto a la introducción del video y mejorar la velocidad en la presentación. } \\
\text { 4) Mejorar la resolución del video. } \\
\text { 5) Mejorar el hipervínculo explicativo de las imágenes. } \\
\text { 6) Corregir las faltas ortografía. } \\
\text { 7) Incluir resumen. } \\
\text { 8) Anexar para impresión. } \\
\text { 9) Valorar la inclusión del glosario. } \\
\text { 10) Cambiar el color del fondo a otro más atractivo. }\end{array}$} \\
\hline
\end{tabular}

Nota: Calificación del 1 al 5: 5 = Excelente, $4=$ Muy bueno, $3=$ Bueno, $2=$ Regular, $1=$ Malo)

Fuente: Elaboración propia

\section{Evaluación del Prototipo vfinal}

Se confeccionó una planilla con preguntas pertinentes a diferentes criterios, tomando como base la utilidad, aspectos pedagógicos y didácticos, así como técnicos. Las preguntas se ponderaron como en los apartados anteriores.

Por último, se solicitó algunas sugerencias a los usuarios mediante un ítem abierto, ya sea para el uso del programa o para realizar algún cambio que se considere pertinente. Los resultados obtenidos se observan en la tabla 3. En general, a partir de la evaluación del programa, hubo aceptación y acuerdo respecto de los cambios producidos en las etapas 


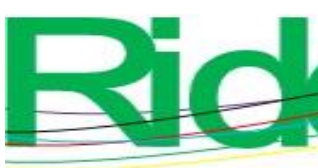

\section{Revista Iberoamericana para la
Investigación y el Desarrollo Educativo ISSN $2007-7467$}

anteriores; los comentarios validaron la facilidad del uso, la importante mejora en los contenidos y la navegación, lo cual, en suma, motivaba a los usuarios por las necesidades actuales del aprendizaje del tópico en cuestión. Debido a la descripción de los temas, el dinamismo e interactividad, fue necesario el desplazamiento de las barras del software.

Tabla 3. Evaluación de desarrollo del software educativo para la orientación-aprendizaje de la detección del cáncer cervicouterino. Prototipo vfinal

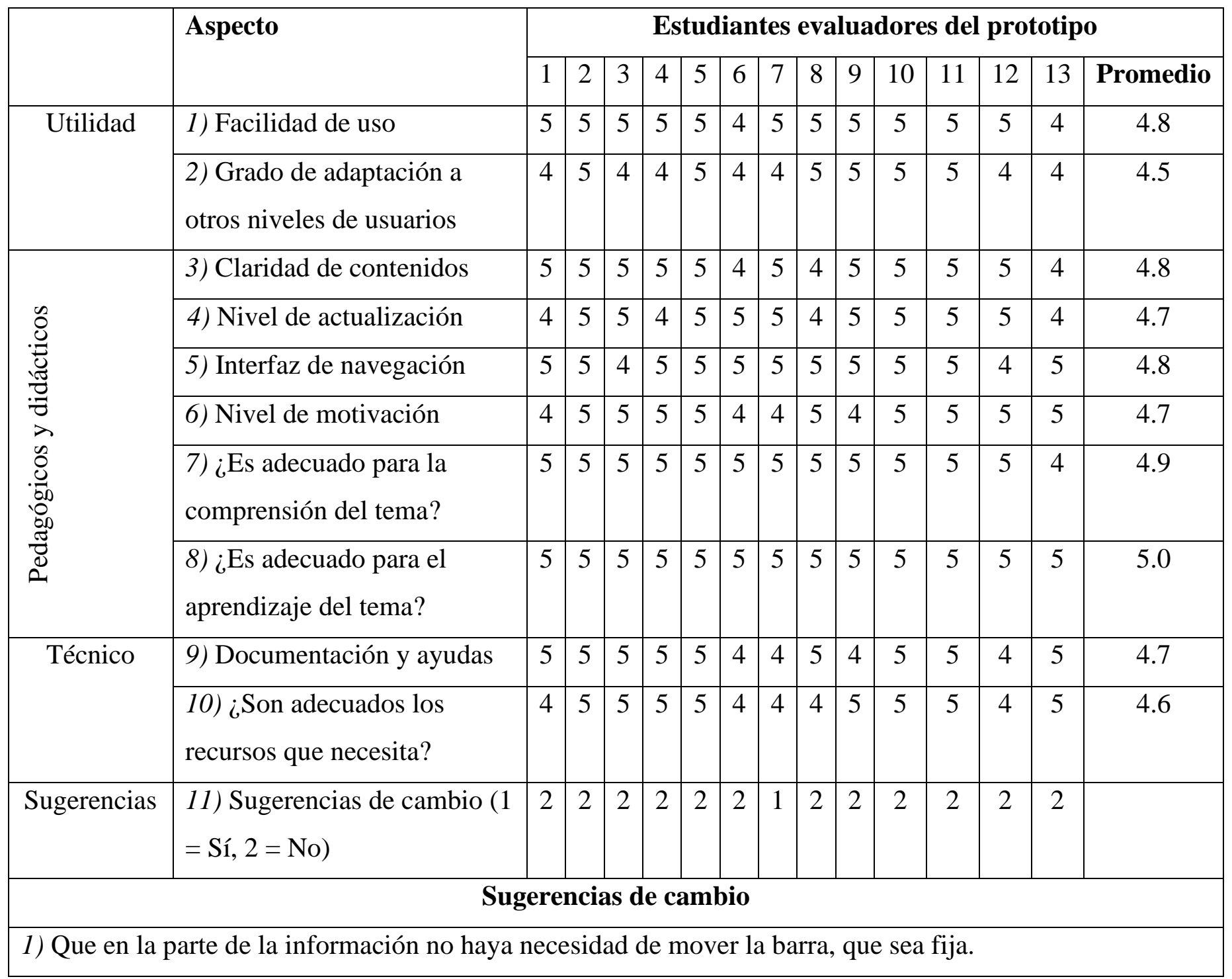

Nota: Calificación del 1 al 5: 5 = Excelente, 4 = Muy bueno, 3 = Bueno, 2 = Regular, 1 = Malo)

Fuente: Elaboración propia 

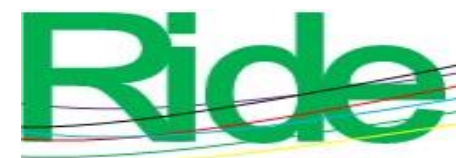

Revista Iberoamericana para la Investigación y el Desarrollo Educativo ISSN 2007 - 7467

\section{Evaluación interna}

En ocasiones es difícil salir de lo tradicional al desarrollar este tipo de programa. El grupo que trabajó en el desarrollo del programa estuvo de acuerdo con los cambios propuestos por los estudiantes. Además, consideró pertinentes las sugerencias recibidas.

\section{Evaluación externa}

Se presentó el programa a nueve docentes y profesionales vinculados con la salud pública, quienes contaban con grados de especialidad y maestría en el área y quienes, al explorar el software educativo para la orientación-aprendizaje de la detección del cáncer cervicouterino, lo consideraron una herramienta interesante para profundizar los conocimientos acerca del cáncer cervicouterino. Además, a los docentes y profesionales participantes se les proporcionó una planilla similar a las anteriores, con preguntas cerradas y abiertas, y se le pidió que respondieran con base en lo observado en el producto ya terminado.

Los resultados cuantitativos se pueden ver en la tabla 4. En cuanto a las recomendaciones, uno sugirió mejorar el sonido de la voz, otros la necesidad de colocar más imágenes, videos y menos carga en los contenidos, para así tener un diseño aún más amigable, interactivo y atractivo. 
Tabla 4. Evaluación externa del producto final

\begin{tabular}{|c|c|c|c|c|c|c|c|c|c|c|}
\hline \multirow{2}{*}{$\begin{array}{l}\text { Requisitos técnicos, utilidad, aspectos } \\
\text { pedagógicos y didácticos del software } \\
\text { educativo }\end{array}$} & \multicolumn{10}{|c|}{$\begin{array}{c}\text { Docentes y profesionales vinculados con la salud } \\
\text { pública }\end{array}$} \\
\hline & 1 & 2 & 3 & 4 & 5 & 6 & 7 & 8 & 9 & Promedio \\
\hline $\begin{array}{l}\text { 1) ¿Considera adecuado el diseño general de la } \\
\text { pantalla? }\end{array}$ & 4 & 5 & 2 & 3 & 4 & 4 & 1 & 4 & 5 & 3.6 \\
\hline 2) ¿Considera adecuado el uso de las ventanas? & 5 & 5 & 3 & 3 & 5 & 4 & 2 & 4 & 4 & 3.9 \\
\hline 3) ¿Considera adecuado el uso de los botones? & 5 & 5 & 5 & 3 & 4 & 4 & 3 & 4 & 5 & 4.2 \\
\hline 4) ¿Considera adecuado el uso de los colores? & 5 & 5 & 4 & 4 & 5 & 4 & 2 & 4 & 4 & 4.1 \\
\hline $\begin{array}{l}\text { 5) ¿Considera adecuado el uso de los tipos de } \\
\text { letras? }\end{array}$ & 4 & 5 & 1 & 3 & 5 & 4 & 2 & 4 & 4 & 3.6 \\
\hline 6) ¿Considera que el programa es interactivo? & 5 & 5 & 1 & 3 & 5 & 4 & 2 & 4 & 5 & 3.8 \\
\hline 7) ¿Considera la interfaz amigable? & 5 & 5 & 2 & 3 & 5 & 4 & 2 & 4 & 5 & 3.9 \\
\hline $\begin{array}{l}\text { 8) ¿Le da buena información acerca del } \\
\text { recorrido? }\end{array}$ & 5 & 5 & 5 & 3 & 4 & 4 & 3 & 4 & 4 & 4.1 \\
\hline $\begin{array}{l}\text { 9) ¿Considera criteriosa la secuenciación de las } \\
\text { pantallas? }\end{array}$ & 4 & 5 & 5 & 3 & 3 & 4 & 2 & 4 & 3 & 3.7 \\
\hline 10) ¿Es de fácil manejo? & 5 & 5 & 4 & 3 & 5 & 5 & 3 & 4 & 5 & 4.3 \\
\hline $\begin{array}{l}\text { 11) ¿Considera que el uso de los íconos es } \\
\text { correcto? }\end{array}$ & 5 & 5 & 2 & 3 & 5 & 5 & 2 & 4 & 5 & 4.0 \\
\hline $\begin{array}{l}\text { 12) ¿Considera adecuada la selección de los } \\
\text { contenidos? }\end{array}$ & 4 & 5 & 4 & 4 & 5 & 5 & 4 & 4 & 5 & 4.4 \\
\hline $\begin{array}{l}\text { 13) ¿Consideraría adecuado el uso del programa } \\
\text { terminado en otros niveles? }\end{array}$ & 5 & 5 & 3 & 3 & 4 & 4 & 3 & 3 & 5 & 3.9 \\
\hline 14) ¿Quisiera que el programa fuera un tutorial? & 5 & 5 & 3 & 3 & 5 & 5 & 2 & 4 & 5 & 4.1 \\
\hline 15) ¿Le facilita la comprensión acerca del tema? & 5 & 5 & 5 & 4 & 5 & 5 & 3 & 5 & 5 & 4.7 \\
\hline 16) ¿Le gustaría que los videos tuvieran sonido? & 3 & 5 & 3 & 3 & 4 & 5 & 2 & 3 & 5 & 3.7 \\
\hline 17) ¿Ha despertado interés en usted? & 5 & 5 & 3 & 3 & 5 & 5 & 2 & 5 & 5 & 4.2 \\
\hline 18) Sugerencias de cambio $(1=$ Sí, $2=$ No $)$ & 1 & 2 & 1 & 1 & 2 & 2 & 1 & 1 & 2 & \\
\hline \multicolumn{11}{|c|}{ Sugerencias de cambio } \\
\hline \multicolumn{11}{|l|}{$\begin{array}{l}\text { 1) El sonido de la voz durante los videos no es m } \\
\text { 2) Está muy plano el diseño. } \\
\text { 3) Apoyo con imágenes. } \\
\text { 4) Poner más videos. } \\
\text { 5) Diseño más amigable, interactivo, atractivo. } \\
\text { 6) Menos carga en los contenidos. } \\
\text { 7) Mejorar la técnica del Papanicolaou y VPH. }\end{array}$} \\
\hline
\end{tabular}

Nota: Calificación del 1 al 5: 5 = Excelente, 4 = Muy bueno, 3 = Bueno, $2=$ Regular, 1 = Malo)

Fuente: Elaboración propia 


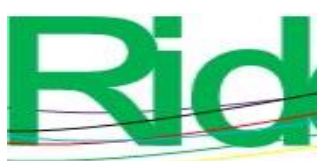

Revista Iberoamericana para la Investigación y el Desarrollo Educativo ISSN 2007 - 7467

\section{Evaluación contextualizada del software educativo para la orientación- aprendizaje de la detección del cáncer cervicouterino}

A continuación, se describen los resultados de la intervención, en donde se presentó el software educativo para la orientación-aprendizaje de la detección del cáncer cervicouterino a los estudiantes de medicina para dar cuenta de la eficacia del producto en cuanto al logro de aprendizajes significativos.

\section{Grupo A (clase tradicional)}

En este grupo, un integrante del grupo presentó el tema, los demás recibieron la información. Algunos, al igual que el coordinador del grupo (profesor), preguntaron y realizaron comentarios en relación con el tema del cáncer cervicouterino.

De los resultados, en cuanto a las generalidades del cáncer cervicouterino (tabla 5), es de resaltar que solo el ítem “¿Cuál es el grupo de edad más afectado por cáncer cervicouterino en México?" en el test de $\mathrm{X}^{2}$ dio un valor de 5.58, una medida de fuerza de asociación (RM) de 4.29 (IC 95\% = 1.25-14.74) y un $p<0.05$ con diferencia estadísticamente significativa; en los demás ítems no se encontraron diferencias estadísticamente significativas. Al promediar la proporción de este grupo de variables, se observó la diferencia porcentual con un ligero incremento de conocimiento (6.38 \%) después de la intervención. 


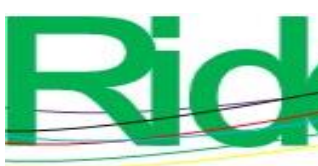

Revista Iberoamericana para la Investigación y el Desarrollo Educativo

ISSN 2007 - 7467

Tabla 5. Determinación de los estudiantes con respuestas correctas de las generalidades del cáncer cervicouterino. Encuesta pretest y postest clase tradicional

\begin{tabular}{|c|c|c|c|c|c|c|c|c|c|}
\hline $\begin{array}{l}\text { Preguntas del tema. } \\
\text { Generalidades }\end{array}$ & $\begin{array}{c}\text { Pretest } \\
(n=23)\end{array}$ & $\%$ & $\begin{array}{c}\text { Postest } \\
(n=23)\end{array}$ & $\%$ & $\mathbf{X}^{2}$ & $\mathbf{R M}$ & $\begin{array}{c}\text { IC } \\
95 \%\end{array}$ & $\mathbf{P}$ & $\begin{array}{c}\text { Prueba } \\
\text { exacta } \\
\text { de } \\
\text { Fisher }\end{array}$ \\
\hline $\begin{array}{l}\text { ¿Qué es el cáncer } \\
\text { cervicouterino? }\end{array}$ & 13 & 56.52 & 14 & 60.87 & 0.00 & 0.98 & $0.31-3.07$ & 0.971 & - \\
\hline $\begin{array}{l}\text { ¿Cuál es el principal } \\
\text { factor de riesgo del cáncer } \\
\text { cervicouterino? }\end{array}$ & 23 & 100.00 & 23 & 100.00 & - & - & - & - & - \\
\hline $\begin{array}{l}\text { ¿A qué edad comúnmente } \\
\text { las mujeres se infectan } \\
\text { con el VPH? }\end{array}$ & 16 & 69.57 & 16 & 69.57 & 0.00 & 1.00 & $0.28-3.51$ & 1.000 & - \\
\hline $\begin{array}{l}\text { ¿Cuál es el grupo de edad } \\
\text { más afectado por cáncer } \\
\text { cervicouterino } \\
\text { México? }\end{array}$ & 7 & 30.43 & 15 & 65.22 & 5.58 & 4.29 & $1.25-14.74$ & 0.018 & - \\
\hline $\begin{array}{l}\text { Dentro de las muertes por } \\
\text { neoplasia en mujeres en } \\
\text { México, ¿qué lugar ocupa } \\
\text { el cáncer cervicouterino? }\end{array}$ & 7 & 30.43 & 13 & 56.52 & 3.18 & 2.97 & $0.88-9.98$ & 0.074 & - \\
\hline $\begin{array}{l}\text { ¿Qué es la citología } \\
\text { cervical? }\end{array}$ & 8 & 34.78 & 4 & 17.39 & - & 0.39 & $0.10-1.57$ & - & 0.3140 \\
\hline $\begin{array}{l}\text { ¿Quién confirma el } \\
\text { diagnóstico citológico de } \\
\text { una probable lesión } \\
\text { cervical? }\end{array}$ & 12 & 52.17 & 10 & 43.48 & 0.35 & 0.71 & $0.22-2.25$ & 0.555 & - \\
\hline $\begin{array}{l}\text { En México, ¿cuál es la } \\
\text { norma oficial que se } \\
\text { refiere a la prevención, } \\
\text { detección, diagnóstico, } \\
\text { tratamiento, control y } \\
\text { vigilancia epidemiológica } \\
\text { del cáncer } \\
\text { cervicouterino? }\end{array}$ & 8 & 34.78 & 5 & 21.74 & 0.97 & 0.52 & $0.14-1.93$ & 0.326 & - \\
\hline Promedio & & 51.09 & & 54.35 & & & & & \\
\hline
\end{tabular}

Fuente: Elaboración propia

En relación con la determinación de los estudiantes con respuestas correctas sobre la citología cervical (tabla 6), los ítems de este apartado con la medida de asociación elevada resultaron: “¿Cuándo está contraindicado tomar la citología cervical?” (una RM de 2.35, no estadísticamente significativa) y "Si la usuaria está histerectomizada, ¿de donde tomará la muestra de Papanicolaou? (con una RM de 5.13 (IC $95 \%=1.18-22.24$ ) y un $p<0.05$ con 


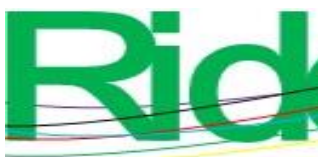

\section{Revista Iberoamericana para la Investigación y el Desarrollo Educativo ISSN 2007 - 7467}

diferencia estadísticamente significativa. En los demás ítems no se encontraron diferencias estadísticamente significativas. Al promediar la proporción de este grupo de variables, se observó la diferencia porcentual con un ligero incremento de conocimiento de $16.67 \%$ después de la intervención.

Tabla 6. Determinación de los estudiantes con respuestas correctas sobre la citología cervical. Encuesta pretest y postest. Clase tradicional

\begin{tabular}{|c|c|c|c|c|c|c|c|c|c|}
\hline $\begin{array}{l}\text { Preguntas del tema } \\
\text { citología cervical }\end{array}$ & $\begin{array}{c}\text { Pretest } \\
(n=23)\end{array}$ & $\%$ & $\begin{array}{l}\text { Postest } \\
(n=23)\end{array}$ & $\%$ & $\mathbf{X}^{2}$ & $\mathbf{R M}$ & $\begin{array}{c}\text { IC } \\
95 \%\end{array}$ & $\mathbf{P}$ & $\begin{array}{c}\text { Prueba } \\
\text { exacta } \\
\text { de } \\
\text { Fisher }\end{array}$ \\
\hline $\begin{array}{l}\text { ¿Cuáles son los factores } \\
\text { de riesgo del cáncer } \\
\text { cervicouterino? }\end{array}$ & 12 & 52.17 & 15 & 65.22 & 0.3 & 1.38 & $0.44-4.32$ & 0.585 & - \\
\hline $\begin{array}{l}\text { ¿Cuándo está } \\
\text { contraindicado tomar la } \\
\text { citología cervical? }\end{array}$ & 17 & 73.91 & 20 & 86.96 & - & 2.35 & $0.51-10.86$ & - & 0.4590 \\
\hline $\begin{array}{l}\text { Para la prueba de } \\
\text { Papanicolaou, ¿de dónde } \\
\text { se toma la muestra de } \\
\text { células? }\end{array}$ & 7 & 30.43 & 10 & 43.48 & 0.84 & 1.76 & $0.52-5.91$ & 0.3594 & - \\
\hline $\begin{array}{l}\text { ¿En dónde se deben } \\
\text { registrar los datos } \\
\text { completos de la usuaria } \\
\text { para la prueba de } \\
\text { Papanicolaou? }\end{array}$ & 15 & 65.22 & 14 & 60.87 & 0.09 & 0.83 & $0.25-2.75$ & 0.760 & - \\
\hline $\begin{array}{l}\text { ¿Qué datos de } \\
\text { identificación se deben } \\
\text { anotar en la laminilla? }\end{array}$ & 21 & 91.30 & 18 & 78.26 & - & 0.34 & $0.06-1.99$ & - & 0.4140 \\
\hline $\begin{array}{l}\mathrm{Si} \text { la usuaria está } \\
\text { histerectomizada, ¿de } \\
\text { dónde tomará la muestra } \\
\text { de Papanicolaou? }\end{array}$ & 3 & 13.04 & 10 & 43.48 & - & 5.13 & $1.18-22.24$ & - & 0.0471 \\
\hline $\begin{array}{l}\text { ¿En qué tiempo se debe } \\
\text { realizar la inmersión de la } \\
\text { muestra citológica } \\
\text { cervical en alcohol de } \\
96^{\circ} \text { ? }\end{array}$ & 15 & 65.22 & 18 & 78.26 & 0.97 & 1.92 & $0.52-7.12$ & 0.3259 & - \\
\hline Promedio & & 55.90 & & 65.22 & & & & & \\
\hline
\end{tabular}

Fuente: Elaboración propia

Respecto a la determinación de los estudiantes con respuestas correctas en el apartado dedicado a la toma de la muestra para la detección del VPH por captura de híbridos (tabla 7), 
los ítems de este apartado no mostraron diferencias estadísticamente significativas, aunque el ítem “¿En dónde debe insertar el cepillo y a qué profundidad para la toma de la muestra de ADN del VPH por captura de híbridos?” resultó con una RM de 4.59. Al promediar la proporción de este grupo de variables, se observó la diferencia porcentual de $9.19 \%$ de incremento en conocimiento después de la intervención.

Tabla 7. Determinación de los estudiantes con respuestas correctas sobre la toma de la muestra para la detección del VPH por captura de híbridos. Encuesta pretest y postest.

Clase tradicional

\begin{tabular}{|c|c|c|c|c|c|c|c|c|c|}
\hline $\begin{array}{c}\text { Preguntas sobre la } \\
\text { toma de la muestra } \\
\text { para la detección del } \\
\text { VPH por captura de } \\
\text { híbridos } \\
\end{array}$ & $\begin{array}{c}\text { Pretest } \\
(n=23)\end{array}$ & $\%$ & $\begin{array}{c}\text { Postest } \\
(n=23)\end{array}$ & $\%$ & $\mathbf{X}^{2}$ & $\mathbf{R M}$ & $\begin{array}{c}\text { IC } \\
95 \%\end{array}$ & $\mathbf{P}$ & $\begin{array}{c}\text { Prueba } \\
\text { exacta } \\
\text { de } \\
\text { Fisher }\end{array}$ \\
\hline $\begin{array}{l}\text { ¿Cuáles son } \text { los } \\
\text { requisitos para poder } \\
\text { realizar la toma de } \\
\text { muestra de detección del } \\
\text { ADN del VPH? }\end{array}$ & 16 & 69.57 & 16 & 69.57 & 0.00 & 1.00 & $0.28-3.51$ & 1.000 & - \\
\hline $\begin{array}{l}\text { ¿En dónde se registran } \\
\text { los datos de la usuaria } \\
\text { para poder realizar la } \\
\text { toma de muestra de } \\
\text { detección del ADN del } \\
\text { VPH? }\end{array}$ & 16 & 69.57 & 16 & 69.57 & 0.00 & 1.00 & $0.28-3.51$ & 1.000 & - \\
\hline $\begin{array}{l}\text { ¿En dónde se recolecta } \\
\text { la muestra de la } \\
\text { detección del ADN del } \\
\text { VPH por captura de } \\
\text { híbridos? }\end{array}$ & 11 & 47.83 & 14 & 60.87 & 0.79 & 1.7 & $0.53-5.47$ & 0.3745 & - \\
\hline $\begin{array}{l}\text { ¿En dónde debe insertar } \\
\text { el cepillo y a que } \\
\text { profundidad para la } \\
\text { toma de la muestra de } \\
\text { ADN del VPH por } \\
\text { captura de híbridos? }\end{array}$ & 16 & 69.57 & 21 & 91.30 & - & 4.59 & $0.84-25.17$ & - & 0.1345 \\
\hline $\begin{array}{l}\text { ¿A qué temperatura } \\
\text { deben conservarse el kit } \\
\text { con la muestra? }\end{array}$ & 17 & 73.91 & 16 & 69.57 & 0.11 & 0.81 & $0.22-2.92$ & 0.7433 & - \\
\hline Promedio & & 66.09 & & 72.17 & & & & & \\
\hline
\end{tabular}

Fuente: Elaboración propia 

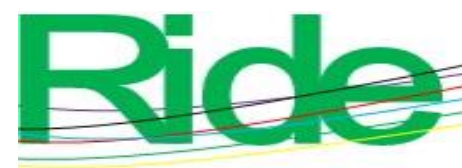

Revista Iberoamericana para la Investigación y el Desarrollo Educativo

ISSN $2007-7467$

En general, en este grupo, en lo que respecta al tema de las generalidades del cáncer cervicouterino, citología cervical y la toma de la muestra para la detección del VPH, al promediar sus proporciones resultó la encuesta pretest con $56.52 \%$ y $62.61 \%$ en la encuesta postest. Al obtener la diferencia porcentual, se observó un incremento de $10.77 \%$ del conocimiento después de la intervención.

\section{Grupo B (clase tradicional y utilización del software educativo para la orientación- aprendizaje de la detección del cáncer cervicouterino)}

En este grupo, un integrante presentó el tema, los demás recibieron la información. Algunos, al igual que el coordinador del grupo (profesor), preguntaron y realizaron algunos comentarios en relación con el cáncer cervicouterino. Además, el profesor entregó a los estudiantes el software educativo para la orientación-aprendizaje de la detección del cáncer cervicouterino para que estudiaran y observaran los temas, imágenes y videos como complemento del tema.

En cuanto a los resultados de la encuesta pretest y postest referentes a las generalidades del cáncer cervicouterino (tabla 8), el ítem “¿Qué es la citología cervical?”, en el test de $\mathrm{X}^{2}$, arrojó un valor de 8.01, una RM de 5.46 (IC $95 \%=1.63-18.36$ ) y un $p<0.05$ con diferencia estadísticamente significativa. "En México, ¿cuál es la norma oficial que se refiere a la prevención, detección, diagnóstico, tratamiento, control y vigilancia epidemiológica del cáncer cervicouterino?”, arrojó un X² de 5.13, una RM de 3.78 (IC 95 \% $=1.17-12.19)$ y un $p<0.05$ con diferencia estadísticamente significativa. En los demás ítems no se encontraron diferencias estadísticamente significativas. Al promediar la proporción de este grupo de variables, se observó la diferencia porcentual de $12.70 \%$ de incremento en conocimiento después de la intervención. 


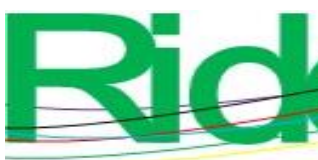

Revista Iberoamericana para la Investigación y el Desarrollo Educativo

ISSN 2007 - 7467

Tabla 8. Determinación de los estudiantes con respuestas correctas de las generalidades del cáncer cervicouterino. Encuesta pretest y postest. Clase tradicional utilizando la herramienta desarrollada

\begin{tabular}{|c|c|c|c|c|c|c|c|c|c|}
\hline $\begin{array}{l}\text { Preguntas del tema. } \\
\text { Generalidades }\end{array}$ & $\begin{array}{l}\text { Pretest } \\
(n=25)\end{array}$ & $\%$ & $\begin{array}{l}\text { Postest } \\
(n=25)\end{array}$ & $\%$ & $\mathbf{X}^{2}$ & RM & IC $95 \%$ & $\mathbf{P}$ & $\begin{array}{c}\text { Prueba } \\
\text { exacta } \\
\text { de } \\
\text { Fisher }\end{array}$ \\
\hline $\begin{array}{l}\text { ¿Qué es el cáncer } \\
\text { cervicouterino? }\end{array}$ & 18 & 72.00 & 16 & 64.00 & 0.37 & 0.69 & $0.21-2.29$ & 0.5442 & - \\
\hline $\begin{array}{l}\text { ¿Cuál es el principal } \\
\text { factor de riesgo del cáncer } \\
\text { cervicouterino? }\end{array}$ & 24 & 96.00 & 25 & 100.00 & - & _- & - & - & 1.0000 \\
\hline $\begin{array}{l}\text { ¿A qué edad comúnmente } \\
\text { las mujeres se infectan } \\
\text { con el VPH? }\end{array}$ & 22 & 88.00 & 19 & 76.00 & - & 0.43 & $0.09-1.97$ & - & 0.4634 \\
\hline $\begin{array}{l}\text { ¿Cuál es el grupo de edad } \\
\text { más afectado por cáncer } \\
\text { cervicouterino } \\
\text { México? }\end{array}$ & 13 & 52.00 & 11 & 44.00 & 0.32 & 0.73 & $0.24-2.21$ & 0.5713 & - \\
\hline $\begin{array}{l}\text { Dentro de las muertes por } \\
\text { neoplasia en mujeres en } \\
\text { México, ¿qué lugar ocupa } \\
\text { el cáncer cervicouterino? }\end{array}$ & 15 & 60.00 & 16 & 64.00 & 0.08 & 1.19 & $0.38-3.72$ & 0.7707 & - \\
\hline $\begin{array}{l}\text { ¿Qué es la citología } \\
\text { cervical? }\end{array}$ & 8 & 32.00 & 18 & 72.00 & 8.01 & 5.46 & $1.63-18.36$ & 0.0046 & - \\
\hline $\begin{array}{l}\text { ¿Quién confirma el } \\
\text { diagnóstico citológico de } \\
\text { una probable lesión } \\
\text { cervical? }\end{array}$ & 17 & 68.00 & 20 & 80.00 & 0.94 & 1.88 & $0.52-6.84$ & 0.3334 & - \\
\hline $\begin{array}{l}\text { En México, ¿cuál es la } \\
\text { norma oficial que se } \\
\text { refiere a la prevención, } \\
\text { detección, diagnóstico, } \\
\text { tratamiento, control y } \\
\text { vigilancia epidemiológica } \\
\text { del cáncer } \\
\text { cervicouterino? }\end{array}$ & 9 & 36.00 & 17 & 68.00 & 5.13 & 3.78 & $1.17-12.19$ & 0.0235 & - \\
\hline Promedio & & 63.00 & & 71.00 & & & & & \\
\hline
\end{tabular}

Fuente: Elaboración propia

En relación con la determinación de los alumnos con respuestas correctas sobre la citología cervical (tabla 9), los ítems que resultaron estadísticamente significativos son los siguientes: “¿Cuáles son los factores de riesgo del cáncer cervicouterino?” resultó con un $\mathrm{X}^{2}$ de 3.95, una RM de 3.19 (IC $95 \%=1.00-10.17$ ) y un $p<0.05$ con diferencia 

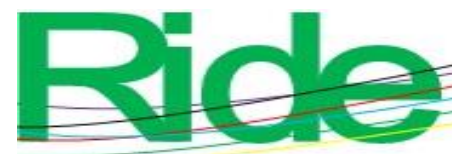

estadísticamente significativa. "Para la prueba de Papanicolaou, ¿de dónde se toma la muestra de células?", la X ${ }^{2}$ resultó con 6.88 , una RM de 5.09 (IC $95 \%=1.45-17.92$ ) y un $p$ $<0.05$ con diferencia estadísticamente significativa. Por su parte, “¿En dónde se deben registrar los datos completos de la usuaria para la prueba de Papanicolaou?", esta relación es estadísticamente significativa (test exacto de Fisher $p=0.0046$ ), una RM de 16.00 (IC $95 \%$ = 1.86-137.98). En lo que se refiere al ítem "Si la usuaria está histerectomizada, ¿de dónde tomará la muestra de Papanicolaou?", arrojó en la prueba exacta de Fisher un $p=0.0374$, una RM de 6.47 (IC $95 \%=1.23-34.01$ ) con diferencia estadísticamente significativa. En los demás ítems no se encontraron diferencias estadísticamente significativas. Al promediar la proporción de este grupo de variables, se observó 53.84 \% de incremento en conocimiento después de la intervención. 
Tabla 9. Determinación de los estudiantes con respuestas correctas sobre la citología cervical. Encuesta pretest y postest. Clase tradicional utilizando la herramienta desarrollada

\begin{tabular}{|c|c|c|c|c|c|c|c|c|c|}
\hline $\begin{array}{l}\text { Preguntas del tema } \\
\text { citología cervical }\end{array}$ & $\begin{array}{c}\text { Pretest } \\
(n=25)\end{array}$ & $\%$ & $\begin{array}{l}\text { Postest } \\
(n=25)\end{array}$ & $\%$ & $\mathbf{X}^{2}$ & $\mathbf{R M}$ & IC $95 \%$ & $\mathbf{P}$ & $\begin{array}{c}\text { Prueba } \\
\text { exacta } \\
\text { de } \\
\text { Fisher }\end{array}$ \\
\hline $\begin{array}{l}\text { ¿Cuáles son los } \\
\text { factores de riesgo del } \\
\text { cáncer } \\
\text { cervicouterino? }\end{array}$ & 10 & 40.00 & 17 & 68.00 & 3.95 & 3.19 & $1.00-10.17$ & 0.0470 & - \\
\hline $\begin{array}{l}\text { ¿Cuándo está } \\
\text { contraindicado tomar } \\
\text { la citología cervical? }\end{array}$ & 16 & 64.00 & 21 & 84.00 & - & 2.95 & $0.77-11.34$ & - & 0.1963 \\
\hline $\begin{array}{l}\text { Para la prueba de } \\
\text { Papanicolaou, ¿de } \\
\text { dónde se toma la } \\
\text { muestra de células? }\end{array}$ & 5 & 20.00 & 14 & 56.00 & 6.88 & 5.09 & $1.45-17.92$ & 0.0087 & - \\
\hline $\begin{array}{l}\text { ¿En dónde se deben } \\
\text { registrar los datos } \\
\text { completos de la } \\
\text { usuaria para la prueba } \\
\text { de Papanicolaou? }\end{array}$ & 15 & 60.00 & 24 & 96.00 & - & 16.00 & $1.86-137.98$ & - & 0.0046 \\
\hline $\begin{array}{lll}\text { ¿Qué datos } & \text { de } \\
\text { identificación } & \text { se } \\
\text { deben anotar en la } \\
\text { laminilla? }\end{array}$ & 16 & 64.00 & 17 & 68.00 & 0.09 & 1.20 & $0.37-3.86$ & 0.7652 & - \\
\hline $\begin{array}{lr}\text { Si la usuaria está } \\
\text { histerectomizada, ¿de } \\
\text { dónde tomará la } \\
\text { muestra } & \text { de } \\
\text { Papanicolaou? } & \\
\end{array}$ & 2 & 8.00 & 9 & 36.00 & - & 6.47 & $1.23-34.01$ & - & 0.0374 \\
\hline $\begin{array}{l}\text { ¿En qué tiempo se } \\
\text { debe realizar la } \\
\text { inmersión de la } \\
\text { muestra de citológica } \\
\text { cervical en alcohol de } \\
96^{\circ} \text { ? }\end{array}$ & 14 & 56.00 & 18 & 72.00 & 1.39 & 2.02 & $0.62-6.56$ & 0.2385 & - \\
\hline Promedio & & 44.57 & & 68.57 & & & & & \\
\hline
\end{tabular}

Fuente: Elaboración propia

Respecto a la determinación de los estudiantes con respuestas correctas en cuanto a la toma de la muestra para la detección del VPH por captura de híbridos (tabla 10), en los ítems de este apartado no se encontraron diferencias estadísticamente significativas; sin embargo, el ítem “¿En dónde se registran los datos de la usuaria para poder realizar la toma de muestra de detección del ADN del VPH?”, resultó con una RM de 2.30. Al promediar la 


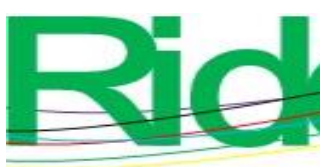

Revista Iberoamericana para la Investigación y el Desarrollo Educativo

ISSN $2007-7467$

proporción de este grupo de variables, se observó $13.33 \%$ de incremento de conocimiento después de la intervención.

Tabla 10. Determinación de los estudiantes con respuestas correctas sobre la toma de la muestra para la detección del VPH por captura de híbridos. Encuesta pretest y postest.

Clase tradicional utilizando la herramienta desarrollada.

\begin{tabular}{|c|c|c|c|c|c|c|c|c|c|}
\hline $\begin{array}{c}\text { Preguntas sobre la } \\
\text { toma de la muestra } \\
\text { para la detección del } \\
\text { VPH por captura de } \\
\text { híbridos } \\
\end{array}$ & $\begin{array}{c}\text { Pretest } \\
(n=25)\end{array}$ & $\%$ & $\begin{array}{l}\text { Postest } \\
(n=25)\end{array}$ & $\%$ & $\mathbf{X}^{2}$ & $\mathbf{R M}$ & IC $95 \%$ & $\mathbf{P}$ & $\begin{array}{c}\text { Prueba } \\
\text { exacta } \\
\text { de } \\
\text { Fisher }\end{array}$ \\
\hline $\begin{array}{l}\text { ¿Cuáles son los } \\
\text { requisitos para poder } \\
\text { realizar la toma de } \\
\text { muestra de detección } \\
\text { del ADN del VPH? }\end{array}$ & 11 & 44.00 & 15 & 60.00 & 1.28 & 1.91 & $0.62-5.88$ & 0.2575 & - \\
\hline $\begin{array}{l}\text { ¿En dónde se registran } \\
\text { los datos de la usuaria } \\
\text { para poder realizar la } \\
\text { toma de muestra de } \\
\text { detección del ADN del } \\
\text { VPH? }\end{array}$ & 12 & 48.00 & 17 & 68.00 & 2.05 & 2.30 & $0.73-7.27$ & 0.1519 & - \\
\hline $\begin{array}{l}\text { ¿En dónde se recolecta } \\
\text { la muestra de la } \\
\text { detección del ADN del } \\
\text { VPH por captura de } \\
\text { híbridos? }\end{array}$ & 19 & 76.00 & 16 & 64.00 & 0.86 & 0.56 & $0.16-1.92$ & 0.3570 & - \\
\hline $\begin{array}{l}\text { ¿En dónde debe } \\
\text { insertar el cepillo y a } \\
\text { qué profundidad para } \\
\text { la toma de la muestra } \\
\text { de ADN del VPH por } \\
\text { captura de híbridos? }\end{array}$ & 19 & 76.00 & 21 & 84.00 & - & 1.66 & $0.41-6.79$ & - & 0.7252 \\
\hline $\begin{array}{l}\text { ¿A qué temperatura } \\
\text { deben conservarse los } \\
\text { kit con la muestra? }\end{array}$ & 14 & 56.00 & 16 & 64.00 & 0.33 & 1.4 & $0.45-4.35$ & 0.5637 & - \\
\hline Promedio & & 60.00 & & 68.00 & & & & & \\
\hline
\end{tabular}

Fuente: Elaboración propia

En general, al promediar las proporciones de este grupo, la encuesta pretest resultó con $55.8 \%$, mientras que se observó $69.4 \%$ en la encuesta postest. Como se puede observar, hay una diferencia porcentual y un incremento de $24.37 \%$ del conocimiento después de la intervención. 


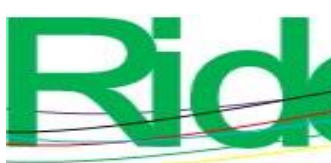

Revista Iberoamericana para la Investigación y el Desarrollo Educativo ISSN 2007 - 7467

\section{Grupo C (utilización del software educativo para la orientación-aprendizaje de la detección del cáncer cervicouterino)}

En este grupo, el coordinador del grupo les indicó a los alumnos estudiar el tema de cáncer cervicouterino señalado en el programa de la asignatura de Salud Pública. Además, el profesor les entregó el software educativo para la orientación-aprendizaje de la detección del cáncer cervicouterino para el estudio del tema, por lo que deberían revisar los tópicos, imágenes, videos, entre otros, del software.

Los resultados de la encuesta pretest y postest de las generalidades del cáncer cervicouterino de los ítems con respuestas correctas (tabla 11) que resultaron con asociación considerable fueron: “¿A qué edad comúnmente las mujeres se infectan con el VPH?” (RM de 1.56), "Dentro de las muertes por neoplasia en mujeres en México, ¿qué lugar ocupa el cáncer cervicouterino?” (RM 2.67), “QQué es la citología cervical?” (RM de 9.0), “¿Quién confirma el diagnóstico citológico de una probable lesión cervical?" (RM de 1.7) y "En México, ¿cuál es la norma oficial que se refiere a la prevención, detección, diagnóstico, tratamiento, control y vigilancia epidemiológica del cáncer cervicouterino?" (RM de 9.0), lo cual sugiere la efectividad del software en el incremento del conocimiento, aunque ningún ítem resultó estadísticamente significativo. Al promediar la proporción de este grupo de variables, la diferencia porcentual resultó con $21.74 \%$ de incremento de conocimiento después de la intervención. 
Tabla 11. Determinación de los estudiantes con respuestas correctas respecto a las generalidades del cáncer cervicouterino. Encuesta pretest y postest. Se utilizó la herramienta desarrollada

\begin{tabular}{|c|c|c|c|c|c|c|c|c|c|}
\hline $\begin{array}{l}\text { Preguntas del tema. } \\
\text { Generalidades }\end{array}$ & $\begin{array}{c}\text { Pretest } \\
(n=10)\end{array}$ & $\%$ & $\begin{array}{l}\text { Postest } \\
(n=10)\end{array}$ & $\%$ & $X^{2}$ & $\mathbf{R M}$ & IC $95 \%$ & $\mathbf{P}$ & $\begin{array}{c}\begin{array}{c}\text { Prueba } \\
\text { exacta } \\
\text { de } \\
\text { Fisher }\end{array} \\
\end{array}$ \\
\hline $\begin{array}{l}\text { ¿Qué es el cáncer } \\
\text { cervicouterino? }\end{array}$ & 10 & 100.00 & 8 & 80.00 & - & - & - & - & 0.4736 \\
\hline $\begin{array}{l}\text { ¿Cuál es el principal } \\
\text { factor de riesgo del } \\
\text { cáncer cervicouterino? }\end{array}$ & 10 & 100.00 & 10 & 100.00 & - & - & - & - & - \\
\hline $\begin{array}{lr}\text { ¿A qué } & \text { edad } \\
\text { comúnmente } & \text { las } \\
\text { mujeres se infectan } \\
\text { con el VPH? }\end{array}$ & 6 & 60.00 & 7 & 70.00 & - & 1.56 & $0.24-9.91$ & - & 1.0000 \\
\hline $\begin{array}{l}\text { ¿Cuál es el grupo de } \\
\text { edad más afectado por } \\
\text { cáncer cervicouterino } \\
\text { en México? }\end{array}$ & 5 & 50.00 & 5 & 50.00 & 0.00 & 1.00 & $0.17-5.77$ & 1.0000 & - \\
\hline $\begin{array}{l}\text { Dentro de las muertes } \\
\text { por neoplasia en } \\
\text { mujeres en México, } \\
\text { ¿qué lugar ocupa el } \\
\text { cáncer cervicouterino? }\end{array}$ & 6 & 60.00 & 8 & 80.00 & - & 2.67 & $0.36-19.71$ & - & 0.6284 \\
\hline $\begin{array}{l}\text { ¿Qué es la citología } \\
\text { cervical? }\end{array}$ & 1 & 10.00 & 5 & 50.00 & - & 9.00 & $0.81-100.14$ & - & 0.1408 \\
\hline $\begin{array}{l}\text { ¿Quién confirma el } \\
\text { diagnóstico citológico } \\
\text { de una probable lesión } \\
\text { cervical? }\end{array}$ & 7 & 70.00 & 8 & 80.00 & - & 1.71 & $0.22-13.41$ & - & 1.0000 \\
\hline $\begin{array}{l}\text { En México, ¿cuál es la } \\
\text { norma oficial que se } \\
\text { refiere a la prevención, } \\
\text { detección, diagnóstico, } \\
\text { tratamiento, control y } \\
\text { vigilancia } \\
\text { epidemiológica del } \\
\text { cáncer cervicouterino? }\end{array}$ & 1 & 10.00 & 5 & 50.00 & - & 9.00 & $0.81-100.14$ & - & 0.1408 \\
\hline Promedio & & 57.50 & & 70.00 & & & & & \\
\hline
\end{tabular}

\section{Fuente: Elaboración propia}

En relación con las respuestas correctas sobre la citología cervical (tabla 12), los ítems que resultaron con la medida de fuerza de asociación elevados, pero no estadísticamente significativos, son los siguientes: “Cuáles son los factores de riesgo del cáncer 

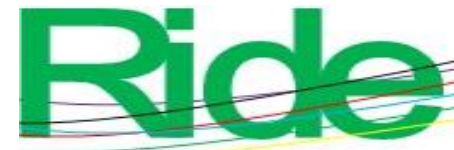

cervicouterino?” (RM de 3.50), "Para la prueba de Papanicolaou, ¿de dónde se toma la muestra de células” (RM de 2.3), “En dónde se deben registrar los datos completos de la usuaria para la prueba de Papanicolaou?” (RM de 6.0) y “¿En qué tiempo se debe realizar la inmersión de la muestra citológica cervical en alcohol de 96²?" (RM de 2.67). Al promediar la proporción de este grupo de variables, se observó la diferencia porcentual de $47.07 \%$ de incremento en conocimiento después de la intervención. 
Tabla 12. Determinación de los estudiantes con respuestas correctas sobre la citología cervical. Encuesta pretest y postest. Se utilizó la herramienta desarrollada

\begin{tabular}{|c|c|c|c|c|c|c|c|c|c|}
\hline $\begin{array}{l}\text { Preguntas del tema } \\
\text { de citología cervical }\end{array}$ & $\begin{array}{c}\text { Pretest } \\
(n=10)\end{array}$ & $\%$ & $\begin{array}{c}\text { Postest } \\
(n=10)\end{array}$ & $\%$ & $\mathbf{X}^{2}$ & $\mathbf{R M}$ & IC $95 \%$ & $\mathbf{P}$ & $\begin{array}{c}\text { Prueba } \\
\text { exacta } \\
\text { de } \\
\text { Fisher }\end{array}$ \\
\hline $\begin{array}{l}\text { ¿Cuáles son los } \\
\text { factores de riesgo del } \\
\text { cáncer cervicouterino? }\end{array}$ & 4 & 40.00 & 7 & 70.00 & - & 3.50 & $0.55-22.30$ & - & 0.3698 \\
\hline $\begin{array}{l}\text { ¿Cuándo está } \\
\text { contraindicado tomar } \\
\text { la citología cervical? }\end{array}$ & 7 & 70.00 & 10 & 100.00 & - & - & - & - & 0.2105 \\
\hline $\begin{array}{l}\text { Para la prueba de } \\
\text { Papanicolaou, ¿de } \\
\text { dónde se toma la } \\
\text { muestra de células? }\end{array}$ & 1 & 10.00 & 2 & 20.00 & - & 2.25 & $0.17-29.77$ & - & 1.0000 \\
\hline $\begin{array}{l}\text { ¿En dónde se deben } \\
\text { registrar los datos } \\
\text { completos de la } \\
\text { usuaria para la prueba } \\
\text { de Papanicolaou? }\end{array}$ & 6 & 60.00 & 9 & 90.00 & - & 6.00 & $0.53-67.65$ & - & 0.3034 \\
\hline $\begin{array}{ll}\text { ¿Qué datos } & \text { de } \\
\text { identificación } & \text { se } \\
\text { deben anotar en } & \text { la } \\
\text { laminilla? } & \\
\end{array}$ & 10 & 100.00 & 8 & 80.00 & - & - & - & - & 0.4736 \\
\hline $\begin{array}{l}\mathrm{Si} \text { la usuaria está } \\
\text { histerectomizada, ¿de } \\
\text { donde se tomará la } \\
\text { muestra } \\
\text { Papanicolaou? }\end{array}$ & 0 & 0.00 & 6 & 60.00 & - & - & - & - & 0.0108 \\
\hline $\begin{array}{l}\text { ¿En qué tiempo se } \\
\text { debe realizar la } \\
\text { inmersión de la } \\
\text { muestra citológica } \\
\text { cervical en alcohol de } \\
96^{\circ} \text { ? }\end{array}$ & 6 & 60.00 & 8 & 80.00 & - & 2.67 & $0.36-19.71$ & - & 0.6284 \\
\hline Promedio & & 48.57 & & 71.43 & & & & & \\
\hline
\end{tabular}

Fuente: Elaboración propia

Respecto a la determinación de los estudiantes con respuestas correctas relacionadas con la toma de la muestra para la detección del VPH por captura de híbridos (tabla 13), los ítems de este apartado que resultaron con la medida de asociación elevados son los siguientes: “En dónde debe insertar el cepillo y a qué profundidad para la toma de la muestra de ADN del VPH por captura de híbridos” (RM de 3.86) y “¿A qué temperatura deben conservarse el 


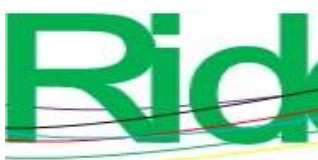

\section{Revista Iberoamericana para la Investigación y el Desarrollo Educativo ISSN 2007 - 7467}

kit con la muestra?" (RM de 3.50), aunque no se encontraron diferencias estadísticamente significativas. Al promediar la proporción de este grupo de variables, se observó la diferencia porcentual de $24.13 \%$ de incremento en conocimiento después de la intervención.

Tabla 13. Determinación de los estudiantes con respuestas correctas respecto a la muestra para la detección del VPH por captura de híbridos. Encuesta pretest y postest clase tradicional. Se utilizó la herramienta desarrollada

\begin{tabular}{|c|c|c|c|c|c|c|c|c|c|}
\hline $\begin{array}{c}\text { Preguntas sobre la } \\
\text { toma de la muestra } \\
\text { para la detección del } \\
\text { VPH por captura de } \\
\text { híbridos }\end{array}$ & $\begin{array}{c}\text { Pretest } \\
(n=10)\end{array}$ & $\%$ & $\begin{array}{c}\text { Postest } \\
(n=10)\end{array}$ & $\%$ & $\mathbf{X}^{2}$ & $\mathbf{R M}$ & IC $95 \%$ & $\mathbf{P}$ & $\begin{array}{c}\text { Prueba } \\
\text { exacta } \\
\text { de } \\
\text { Fisher }\end{array}$ \\
\hline $\begin{array}{l}\text { ¿Cuáles son los } \\
\text { requisitos para poder } \\
\text { realizar la toma de } \\
\text { muestra de detección } \\
\text { del ADN del VPH? }\end{array}$ & 8 & 80.00 & 8 & 80.00 & - & 1.00 & $0.11-8.95$ & - & 1.4179 \\
\hline $\begin{array}{l}\text { ¿En dónde se registran } \\
\text { los datos de la usuaria } \\
\text { para poder realizar la } \\
\text { toma de muestra de } \\
\text { detección del ADN del } \\
\text { VPH? }\end{array}$ & 6 & 60.00 & 7 & 70.00 & - & 1.56 & $0.24-9.91$ & - & 1.0000 \\
\hline $\begin{array}{l}\text { ¿En dónde se recolecta } \\
\text { la muestra de la } \\
\text { detección del ADN del } \\
\text { VPH por captura de } \\
\text { híbridos? }\end{array}$ & 4 & 40.00 & 5 & 50.00 & - & 1.50 & $0.26-8.82$ & - & 1.0000 \\
\hline $\begin{array}{l}\text { ¿En dónde debe } \\
\text { insertar el cepillo y a } \\
\text { qué profundidad para } \\
\text { la toma de la muestra } \\
\text { de ADN del VPH por } \\
\text { captura de híbridos? }\end{array}$ & 7 & 70.00 & 9 & 90.00 & - & 3.86 & $0.33-45.57$ & - & 0.5820 \\
\hline $\begin{array}{l}\text { ¿A qué temperatura } \\
\text { deben conservarse el } \\
\text { kit con la muestra? }\end{array}$ & 4 & 40.00 & 7 & 70.00 & - & 3.50 & $0.55-22.30$ & - & 0.3698 \\
\hline Promedio & & 58.00 & & 72.00 & & & & & \\
\hline
\end{tabular}

Fuente: Elaboración propia

En general, en este grupo, al promediar el total de sus proporciones, la encuesta pretest arrojó $54.5 \%$ y la encuesta postest $71 \%$. Hubo un incremento de $30.28 \%$ del conocimiento después de la intervención (figura 1). 
Figura 1. Incremento porcentual del conocimiento observado por grupo de estudio, en la encuesta pretest y postest.

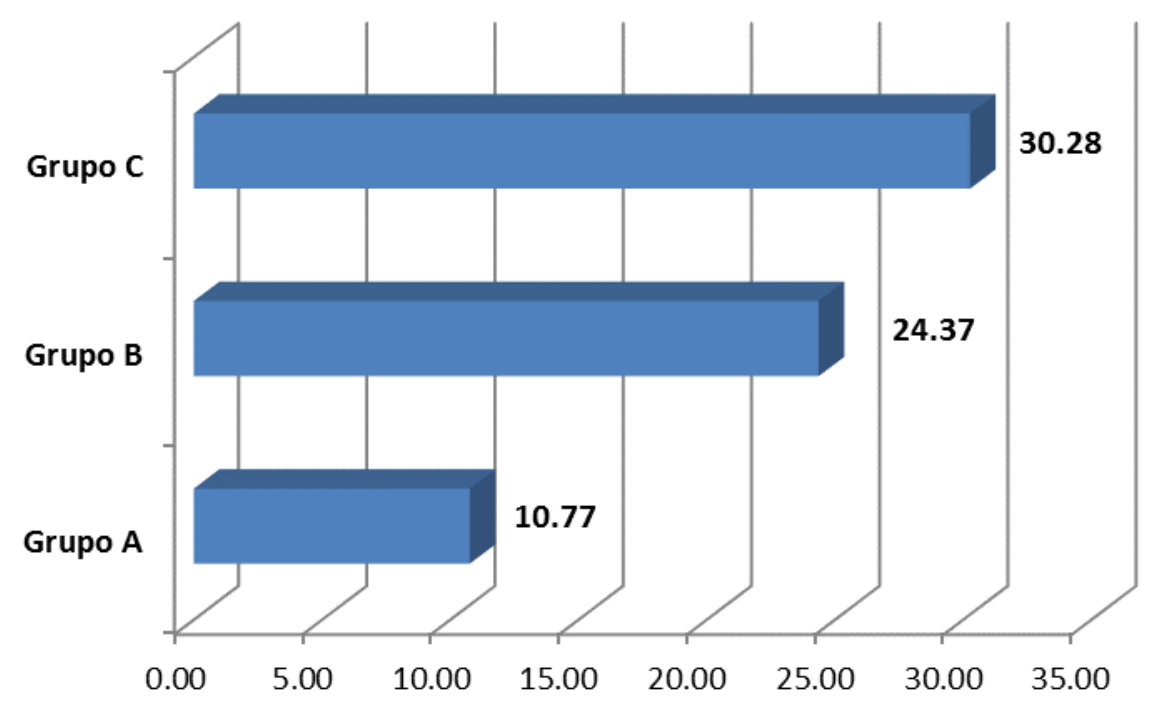

Fuente: Elaboración propia

A partir de lo que se observa en la figura 1, la hipótesis queda explícitamente corroborada, pues el número de estudiantes del grupo B obtuvo una puntuación igual o mayor a $60 \%$, con una RM de 7.88 (IC $95 \%=2.07-29.94$ ) y un $p<0.05$ con diferencia estadísticamente significativa. De igual forma, al analizar los estudiantes con puntuación igual o mayor a $70 \%$, se obtuvo una RM de 20.44 (IC $95 \%=3.89-107.50$ ) y un $p<0.05$ con diferencia estadísticamente significativa (tabla 14).

En relación con el análisis estadístico del grupo C, en donde se experimentó solo con el software educativo para la orientación-aprendizaje de la detección del cáncer cervicouterino, se obtuvieron datos aún mejores en la puntuación de los estudiantes con resultados iguales o mayores a $60 \%$, una RM de 9.33 (IC $95 \%=1.19-72.99$ ) y un $p<0.05$ con diferencia estadísticamente significativa. E igualmente, los estudiantes de este grupo con puntuación igual o mayor a $70 \%$ arrojaron en la prueba exacta de Fisher un 0.0162 (tabla 14).

En lo que respecta al grupo A (grupo control), solo sobresalió la RM (2.49), la cual resultó no estadísticamente significativa en los estudiantes con puntuación igual o mayor de $60 \%$; la $\mathrm{X}^{2}$ (2.24) en el análisis de este grupo no mostró diferencia estadística (tabla 14). 


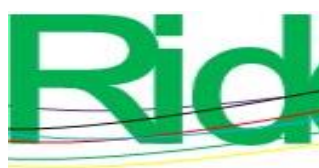

Revista Iberoamericana para la Investigación y el Desarrollo Educativo

ISSN 2007 - 7467

Tabla 14. Determinación de los estudiantes con $60 \%$ y $70 \%$ de puntuación en la evaluación pretest y postest

\begin{tabular}{|c|c|c|c|c|c|c|c|c|c|}
\hline $\begin{array}{l}\text { Grupo A (clase } \\
\text { tradicional) }\end{array}$ & $\begin{array}{c}\text { Pretest } \\
(n=23)\end{array}$ & $\%$ & $\begin{array}{c}\text { Postest } \\
(n=23)\end{array}$ & $\%$ & $\mathbf{X}^{2}$ & $\mathbf{R M}$ & IC $95 \%$ & $\mathbf{P}$ & $\begin{array}{c}\text { Prueba } \\
\text { exacta de } \\
\text { Fisher } \\
\end{array}$ \\
\hline Puntuación $\geq 60 \%$ & 11 & 47.83 & 16 & 69.57 & 2.24 & 2.49 & $0.75-8.34$ & 0.134 & - \\
\hline Puntuación $\geq 70 \%$ & 5 & 21.74 & 6 & 26.09 & 0.12 & 1.27 & $0.33-4.95$ & 0.73 & - \\
\hline $\begin{array}{lr}\text { Grupo B } & \text { (clase } \\
\text { tradicional } & y \\
\text { utilización de la } & \\
\text { herramienta } & \\
\text { desarrollada) } & \\
\end{array}$ & $\begin{array}{c}\text { Pretest } \\
(n=25)\end{array}$ & $\%$ & $\begin{array}{l}\text { Postest } \\
(n=25)\end{array}$ & $\%$ & $\mathbf{X} 2$ & $\mathbf{R M}$ & IC $95 \%$ & $\mathbf{P}$ & $\begin{array}{c}\text { Prueba } \\
\text { exacta de } \\
\text { Fisher }\end{array}$ \\
\hline Puntuación $\geq 60 \%$ & 10 & 40.00 & 21 & 84.00 & 10.27 & 7.88 & $2.07-29.94$ & 0.001 & 0.0015 \\
\hline Puntuación $\geq 70 \%$ & 2 & 8.00 & 16 & 64.00 & 17.01 & 20.44 & $3.89-107.50$ & 0.0000 & 0.0000 \\
\hline $\begin{array}{ll}\text { Grupo } & \text { C } \\
\text { (utilización de la } \\
\text { herramienta } \\
\text { desarrollada) }\end{array}$ & $\begin{array}{c}\text { Pretest } \\
(n=10)\end{array}$ & $\%$ & $\begin{array}{c}\text { Postest } \\
(n=10)\end{array}$ & $\%$ & $\mathbf{X} 2$ & $\mathbf{R M}$ & IC $95 \%$ & $\mathbf{P}$ & $\begin{array}{c}\text { Prueba } \\
\text { exacta de } \\
\text { Fisher }\end{array}$ \\
\hline Puntuación $\geq 60 \%$ & 3 & 30.00 & 8 & 80.00 & 5.05 & 9.33 & $1.19-72.99$ & 0.0246 & 0.0348 \\
\hline Puntuación $\geq 70 \%$ & 0 & 0.00 & 5 & 50.00 & - & - & - & - & 0.0162 \\
\hline
\end{tabular}

Fuente: Elaboración propia

\section{Discusión}

El software educativo realizado metódicamente y con criterios de calidad pedagógica es uno de los pilares en que se sostiene el sistema educativo a distancia (Cataldi, 2006). Además de lo fácil que resulta emplearlo, mantiene el interés y la motivación del estudiante; a causa de su enfoque pedagógico, resulta de relevancia curricular, y un excelente material de aprendizaje; debido a la organización y estructuración de los contenidos y a que cuenta con un enfoque cognitivista, constructivista y conectivista, permite a los estudiantes aprender e incluso autoevaluarse. Naturalmente, frente a esta última variable, se deberá enfatizar en la participación del estudiante en los procesos de evaluación del aprendizaje (Núñez, 2008). Lo anteriormente mencionado debe ser incorporado por los medios electrónicos, realizado por un equipo interdisciplinario, multidisciplinario, y así poder llevar a los estudiantes con un cierto perfil a realizar actividades significativas de aprendizaje (Beauchemin, 2009). 


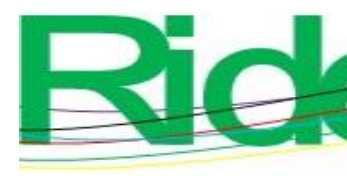

Revista Iberoamericana para la Investigación y el Desarrollo Educativo

ISSN $2007-7467$

La relevancia del presente trabajo gira en torno a que hoy en día constituimos una nueva estructura social en donde imperan los cambios que acompañan a los recursos tecnológicos. En tales términos, el recurso telemático y un manejo de múltiples recursos son una herramienta útil para que el estudiante afiance y logre nuevos aprendizajes de acuerdo con sus expectativas. Aunque, un software o una plataforma digital no es sustituto del profesor o del centro escolar.

La generación de conocimiento utilizando el software como herramienta para el aprendizaje del cáncer cervicouterino se basó en el diseño del ambiente de aprendizaje y la interactividad pensando en el estudiante como ente activo y protagonista en el proceso; en la incorporación de funciones para el fomento de la construcción de conocimiento y la incorporación de funciones para el fomento de habilidades de aprendizaje autorregulado; en apuntar con la debida importancia hacia los elementos pedagógicos relacionados con elementos informáticos y telemáticos necesarios en el uso de las TIC como herramienta para el aprendizaje.

La experiencia de esta investigación deja en claro la relevancia del trabajo colaborativo. En ese sentido, resultó crucial la habilidad de los actores involucrados en la creación del programa educativo (Cataldi, 2000). Además de vincular las áreas del saber, para este tipo de proyectos educativos es fundamental la formación y la conformación de los equipos de desarrollo. El proceso no estuvo exento de momentos difíciles, sobre todo para el docente conocedor del área al momento guiar a los profesionales desarrolladores de software para crear el programa y generar un modelo pedagógico específico de acuerdo con las necesidades solicitadas, con propuestas sólidas que generen experiencias de aprendizaje significativo en ambientes de aprendizaje multimedia (Sandí y Cruz, 2016). Los estudiantes, al utilizar el software educativo para la orientación-aprendizaje de la detección del cáncer cervicouterino que contempló los aspectos pedagógicos para su desarrollo en forma explícita y con contenidos organizados significativamente, obtuvieron un rendimiento superior a la intervención didáctica tradicional utilizada (Cataldi, 2005).

En el análisis comparativo de los grupos A y B, habiendo tomado al A como grupo control, resultó que el grupo B obtuvo un mejor rendimiento en su evaluación gracias a la utilización del software educativo para la orientación-aprendizaje de la detección del cáncer cervicouterino como herramienta de apoyo; aquí, en la ejercitación del tema, se observó que los profesores siguieron la dinámica de la clase tradicional. Mientras que en el grupo C, donde 


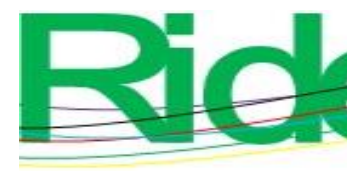

Revista Iberoamericana para la
Investigación y el Desarrollo Educativo
ISSN $2007-7467$

no hubo una intervención tradicional a lo largo de la clase, y solo se utilizó el software educativo para la orientación-aprendizaje de la detección del cáncer cervicouterino, se observó un mejor resultado en el empoderamiento del tema. Por lo tanto, asumimos que la diferencia en términos de rendimiento e incremento de conocimientos se debe a la utilización del software educativo, en particular a la metodología aplicada para su desarrollo, lo que demuestra que los ambientes virtuales de aprendizaje creados con herramientas de enseñanza-aprendizaje adecuadas incrementan el conocimiento del usuario (Dominguez, Bautista, Cárdenas, Amorocho y Montoya, 2019). Aunque no hay que descartar los conocimientos previos del tema de los estudiantes de cada grupo.

\section{Conclusiones}

Tal y como se propuso, se desarrolló un software educativo para la orientaciónaprendizaje de la detección del cáncer cervicouterino donde pudiera apreciarse la toma de la muestra de citología cervical y la toma de muestra para la detección del VPH por captura de híbridos. Como parte de su desarrollo, se consideró oportuno realizar el software interactivo con las siguientes tecnologías: HTML5, JavaScript, jQuery, y para la evaluación se desarrollaron varios prototipos con incremento en las funcionalidades.

Considerando la importancia de algunas teorías del aprendizaje y de sus aportes a las teorías del diseño instruccional en correspondencia con el diseño de materiales didácticos informáticos, se logró construir un software que sirva como referente para implementar un sistema de formación virtual para formar sujetos, más que autodidactas, autónomos. Una parte importante del trabajo es la utilización del hipertexto, lo que repercute cognitivamente en una lectura no lineal, determinada por hipervínculos en la lectura, con enlaces o rutas para navegar en Internet.

Al experimentar con un grupo control y dos experimentales, y al analizar la información recolectada, se obtuvieron resultados positivos: el software diseñado fue capaz de generar un aprendizaje significativo y permitió realizar conexiones lógicas y conceptuales entre los elementos. Al evaluar el conocimiento de los temas contenidos en el software, estas actividades de comprensión pusieron a dialogar el nuevo conocimiento generado por los estudiantes con el previo. 


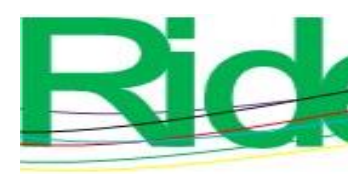

Revista Iberoamericana para la Investigación y el Desarrollo Educativo ISSN $2007-7467$

\section{Referencias}

Beauchemin, M. (2009). Aprendizaje combinado como estrategia didáctica para e-learning en estudiantes universitarios. (tesis doctoral). Universidad Nacional Autónoma de México, Ciudad de México. Recuperado de http://132.248.9.195/ptd2009/octubre/0650358/Index.html.

Cataldi, Z. (2000). Metodología de diseño, desarrollo y evaluación de software educativo. (tesis de magíster). Universidad Nacional de La Plata, La Plata. Recuperado de http://sedici.unlp.edu.ar/bitstream/handle/10915/4055/Documento_completo.pdf?se quence $=20 \&$ is Allowed $=\mathrm{y}$.

Cataldi, Z. (2005). Evaluación de programas hipermedia educativos de producto final y en un contexto similar al de aplicación. Revista Latinoamericana de Tecnología Educativa, 4(2),27-52. Recuperado de https://relatec.unex.es/article/view/511/409.

Cataldi, Z. (2006). El ciclo de vida y la matriz de actividades como base para el diseño y desarrollo metodológico de software educativo. Revista Ingeniería Informática, 13. Recuperado de http://inf.udec.cl/ revista/ediciones/edicion13/articulo\%2013-4.pdf.

Colorado, A. y Edel, N. (2012). La usabilidad TIC en la práctica educativa. Revista de Educación a Distancia, 30(2). Recuperado de http://www.um.es/ead/red/30/edel.pdf.

Dominguez, C., Bautista, L. Cárdenas, M., Amorocho, L. y Montoya, C. (2019). Ambiente virtual de aprendizaje para la capacitación en la toma de la prueba de Papanicolaou. Revista de la Universidad Industrial de Santander, 51(2), 108-117. Recuperado de http://dx.doi.org/10.18273/revsal.v51n2-2019003.

García, E., Vite, O., Navarrate, M. A., García, M. A. y Torres, V. (2016). Metodología para el desarrollo de software multimedia educativo MEDESME. CPU-e, Revista de Investigación Educativa, (23), 216-226. Recuperado de http://www.scielo.org.mx/pdf/cpue/n23/1870-5308-cpue-23-00216.pdf.

Guzmán, J. A., Durley, I. y López, M. (2014) Un caso práctico de aplicación de una metodología para laboratorios virtuales. Scientia Et Technica, 19(1), 67-76. Recuperado de https://www.redalyc.org/pdf/849/84930900011.pdf.

Montana, J. I., Tuena, C., Serino, S., Cipresso, P. and Riva, G. (2019). Neurorehabilitation of Spatial Memory Using Virtual. Environments: A Systematic Review. Journal of Clinical Medicine, 8(10). Retrieved from https://doi.org/10.3390/jcm8101516. 


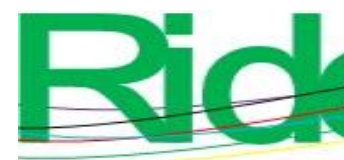

\section{Revista Iberoamericana para la Investigación y el Desarrollo Educativo ISSN 2007 - 7467}

Núñez, R. (2008). Hacia las sociedades del conocimiento. Revista de la Educación Superior. 37(147), 165-173. Recuperado de http://www.scielo.org.mx/scielo.php?pid=S018527602008000300012\&script=sci_arttext.

Olivar, A. y Daza A. (2007). Las tecnologías de la información y comunicación (TIC) y su impacto en la educación del siglo XXI. Revista Negotium / Ciencias Gerenciales. 3(7), 21-46. Recuperado de http://www.revistanegotium.org.ve/pdf/7/Art2.pdf.

Peñalosa, E. y Castañeda, S. (2008). Generación de conocimiento en la educación en línea: Un modelo para el fomento de aprendizaje activo y autorregulado. Revista Mexicana de Investigación Educativa (RMIE), 13(36), 249-281. Recuperado de http://www.scielo.org.mx/pdf/rmie/v13n36/v13n36a11.pdf.

Pérez, J. G. (2002). Elaboración de un modelo de plataforma digital para el aprendizaje y la generación de conocimientos (tesis doctoral). Universidad Complutense de Madrid, Madrid. Recuperado de https://eprints.ucm.es/4623/.

Romero, A. (2014). Cáncer cervicouterino. (software educativo online). Recuperado de http://www.archivos.ujat.mx/libro/.

Romero, A. (2010) Consideraciones para el diseño didáctico de ambientes virtuales de aprendizaje. Horizonte sanitario, 9(3),15-21.

Sandí, D. y Cruz, A. (2016). Propuesta metodológica de enseñanza y aprendizaje para innovar la educación superior. ISUCR, 17(36), 2-38. 


\begin{tabular}{|l|l|}
\hline Rol de Contribución & Autor (es) \\
\hline Conceptualización & Principal: Argeo Romero Vázquez. \\
\hline Metodología & Principal: Argeo Romero Vázquez. \\
\hline Software & Principal: Francisco López Jiménez. \\
\hline Validación & $\begin{array}{l}\text { Principal: Argeo Romero Vázquez. IGUAL: Francisco López } \\
\text { Jiménez }\end{array}$ \\
\hline Análisis Formal & Principal: Argeo Romero Vázquez. \\
\hline Investigación & Principal: Argeo Romero Vázquez. \\
\hline Recursos & Principal: Argeo Romero Vázquez. \\
\hline Curación de datos & $\begin{array}{l}\text { Principal: Francisco López Jiménez. IGUAL: Argeo Romero } \\
\text { Vázquez }\end{array}$ \\
\hline $\begin{array}{l}\text { Escritura - Preparación del } \\
\text { borrador original }\end{array}$ & $\begin{array}{l}\text { Principal: Argeo Romero Vázquez. IGUAL: Francisco López } \\
\text { Jiménez }\end{array}$ \\
\hline Escritura - Revisión y edición & $\begin{array}{l}\text { Principal: Argeo Romero Vázquez. IGUAL: Francisco López } \\
\text { Jiménez }\end{array}$ \\
\hline Visualización & $\begin{array}{l}\text { Principal: Argeo Romero Vázquez. IGUAL: Francisco López } \\
\text { Jiménez }\end{array}$ \\
\hline Supervisión & Principal: Argeo Romero Vázquez. \\
\hline Administración de Proyectos & Principal: Argeo Romero Vázquez. \\
\hline Adquisición de fondos & Principal: Argeo Romero Vázquez. \\
\hline
\end{tabular}

